\title{
Energy Demand and Environment Integration Model and Application: the Case of Beijing
}

\author{
Guo Fangyuan ${ }^{1, a}$ \\ ${ }^{1}$ State Grid Jilin Power Supply Company, China
}

\begin{abstract}
In this paper, energy consumption sector is divided into final energy consumption sector and transformation sector, where final energy consumption sector is divided into six sub-sectors, namely, primary industry sector, industry sector, construction sector, transport sector, service and commerce sector and household sector. Particularly, as a case of urban transport, this paper simulates two scenarios: baseline plan and high plan, and respectively sets three sub-scenarios, namely, developing public transport scenario, fuel replacement scenario and improving vehicle fuel efficiency scenario. LEAP model is used to analyze energy demand and environmental emissions in Beijing till 2025.
\end{abstract}

\section{Introduction}

Beijing is the capital of China, which has large energy consumption. But it is also a city with scarce energy resources and has high dependence on the external. The study of its energy demand and environmental emissions, in particularly energy demand of urban transport, will provide a scientific basis for planning rational energy development strategy and optimizing energy structure.

There are many complete energy models internationally. Top-down energy model reflects viable technology, but underestimates the potential technological progress [1], such as CGE model [2]. Mixed energy model involve a broad range of technology, and therefore there must be a large number of professional researchers and adequate time to complete the complicated project, such as NEMS model [3]. Bottom-up energy model includes LEAP model [4] and so on.

In this paper, LEAP model is used to study energy demand and environmental emissions in Beijing. The remainder of this paper is organized as follows: the second part describes the sector classification, the third part presents the methodology and scenarios settings; the fourth part is the results of the scenario analysis; and the fifth part outlines the conclusions.

\section{Sector classification}

The sector classification in China energy statistical system isn't identical to international energy consumption sector classification. In order to make energy scenario analysis better reflect the characteristics of different energy uses and considering the availability of related technical parameters for energy consumption, this paper

\footnotetext{
a guofangyuan0114@163.com
}

makes an necessary adjustment in the energy consuming sector, based on China Energy Statistical Yearbook.

The industry sector is the main energy consumption sector. To further study energy consumption in the industry sector and taking into account the rapid development of equipment manufactures, this paper focuses on high energy consumption sectors and equipment manufactures with relatively higher energy consumption in the industry sector. Other sectors with lower energy consumption are merged. After the sector adjustment, the industry sector includes six main subsectors: 1) processing of petroleum, coking, processing of nuclear fuel, 2) manufacture of raw chemical materials and chemical products, 3) manufacture of non-metallic mineral products, 4) smelting and pressing of ferrous metals, 5) manufacture of motor vehicles, 6) manufacture of computers, communication equipment and other electronic equipment and others.

Electricity, heat and water production and supply belong to the same statistical category in China statistical system. Electricity and heat production and supply are energy transformation industry, so include the two sectors in the transformation sector. Water production and supply doesn't involve energy transformation process, which is merged with the industry sector.

In China statistical system, the statistics in the transport sector includes only the transportation enterprises engaged in operation. Corresponding energy consumption is only fuel consumption that doesn't include energy consumption of non-operation enterprises and private vehicles. In order to analyze a broad sense of transport energy demand in Beijing, this paper adopts the concept of international general transport. Accordingly, make an adjustment to transport energy consumption data in Beijing Statistical Yearbook. According to specific 
circumstances of each sector, energy consumption in the transport sector includes all gasoline of the primary industry sector, the industry sector, the construction sector, the service and commerce sector and the household sector; $35 \%$ of all diesel of the industry sector, the construction sector, the service and commerce sector; and all diesel of the household sector [5]. After the adjustment, the transport sector is divided into the freight sector and the passenger sector. The passenger sector is divided into the intercity passenger sector and the urban passenger sector. The freight sector and the intercity passenger sector are respectively divided into the airway sector, the railway sector and the highway sector. The most important part focuses on the urban passenger sector, which is classified in accordance with public transport (buses and subway), taxies, official cars and private cars.

After the adjustment, energy consumption sector is divided into final energy consumption sector and transformation sector, where final energy consumption sector is divided into six sub-sectors, namely, primary industry sector, industry sector, construction sector, transport sector, service and commerce sector and household sector.

\section{Methodologies and scenarios}

\subsection{LEAP model}

LEAP model is energy-environment model based on scenario analysis, which is developed by Stockholm Environment Institute. It can calculate energy demand and environmental emissions.

LEAP model consists of two modules. One is final energy demand analysis module, and the other is energy transformation analysis module. In the final energy demand analysis module, energy demand could be calculated from two factors: activity level and final energy intensity in each sector. The energy transformation module is usually run with the final energy demand analysis module, calculating primary energy consumption to balance secondary energy demand generating in the final energy demand analysis module. The model includes a Technology and Environmental Database that describes the technical characteristics and environmental impacts of a range of energy technologies.

\subsection{Regression analysis}

Regression analysis is a quantitative analysis method. This method focuses on quantity changes among the variables and describes the relationship in the form of the regression equation.

If the activity level in the transport sector is set to transport turnover, future energy demand is closely related to the changes of transport turnover. The experiences of many countries' economic development show that economic development isn't separable from the development of the transport sector. There is strong positive correlation between transport turnover and GDP or per capita GDP [6]. To forecast future transport turnover, this paper establishes the regression equations between traffic turnover and GDP or per capita GDP by the history data from 1990 to 2012 in Beijing. Econometric software EViews is used in view of its appropriate for analyzing time series.

\subsection{Scenarios construction}

(1) Population growth

Table 1. Future population in Beijing (million persons)

\begin{tabular}{|c|c|c|c|}
\hline Population & 2015 & 2020 & 2025 \\
\hline Total & 22.05 & 24.69 & 27.05 \\
\hline Urban & 19.32 & 22.22 & 24.89 \\
\hline Rural & 2.73 & 2.47 & 2.16 \\
\hline
\end{tabular}

(2) Evolution of industrial structure

Table 2. The percentage of the value-added of every industry accounting for GDP in Beijing (\%)

\begin{tabular}{|c|c|c|c|}
\hline Sector & 2015 & 2020 & 2025 \\
\hline $\begin{array}{c}\text { Primary } \\
\text { industry }\end{array}$ & 0.70 & 0.63 & 0.52 \\
\hline Industry & 22.00 & 21.05 & 20.53 \\
\hline Construction & 4.16 & 4.07 & 3.86 \\
\hline $\begin{array}{c}\text { Tertiary } \\
\text { industry }\end{array}$ & 73.14 & 74.76 & 75.06 \\
\hline
\end{tabular}

Table 3. The percentage of the value-added of every sector (\%)

\begin{tabular}{|c|c|c|c|}
\hline Sector & 2015 & 2020 & 2025 \\
\hline Petroleum processing & 4.05 & 3.57 & 3.11 \\
\hline Chemical products manufacture & 1.83 & 1.74 & 1.60 \\
\hline $\begin{array}{c}\text { Non-metallic mineral products } \\
\text { manufacture }\end{array}$ & 2.40 & 2.25 & 2.03 \\
\hline Ferrous metals smelting & 0.20 & 0.18 & 0.16 \\
\hline $\begin{array}{c}\text { Motor vehicles manufacture } \\
\text { Communication equipment } \\
\text { manufacture }\end{array}$ & 18.50 & 19.60 & 20.96 \\
\hline \multicolumn{2}{|c|}{} & 11.50 & 12.50 \\
\hline
\end{tabular}

(3) The construction of two scenarios

This paper constructs two scenarios. Scenario 1 is the baseline plan. Scenario 2 is the high plan, which mainly forecasts energy demand and environmental emissions with rapid economic development. Meanwhile, three subscenarios are respectively setting to analyze energy demand and environmental emissions in different urban transport models, namely, developing public transport scenario, fuel replacement scenario and improving vehicle fuel efficiency scenario.

The basic assumptions of scenario 1: the average annual growth rate of GDP will be $7.5 \%$ from 2013 to 2015, 7\% from 2016 to 2020 , and $6.5 \%$ from 2021 to 2025. For the transport sector, in addition to the regression analysis, there are the following assumptions in the urban transport sector: 1) the passenger turnover undertaken by the bus will be 80644 million passengerkilometers in $2025 ; 2$ ) the passenger turnover undertaken by the subway will account for $50 \%$ of the passenger turnover undertaken by the public transport in $2025 ; 3$ ) continue to limit the number of taxis, maintaining the 
same number in 2012; 4) the ownership rate of private cars will increase to 0.8 vehicles per household in 2025 .

The basic assumptions of scenario 2 : the country will put forward a series of policies to promote economic development. The average annual growth rate of GDP will be $7.5 \%$ from 2013 to 2025 . Other assumptions are the same with scenario 1 .

Table 4. Key assumptions of urban transport models

\begin{tabular}{|c|c|}
\hline Sub-s & dels \\
\hline $\begin{array}{l}\text { Scenario 1-1 } \\
(2-1) \\
\text { developing } \\
\text { public } \\
\text { transport }\end{array}$ & $\begin{array}{l}\text { the average annual transport distance } \\
\text { e cars will drop to } 8000 \text { kilometers } \\
\text { is part of passenger turnover will be } \\
\text { by the subway with the development } \\
\text { blic transport. }\end{array}$ \\
\hline $\begin{array}{l}\text { Scenario 1-2 } \\
\quad(2-2) \\
\text { fuel } \\
\text { replacement }\end{array}$ & $\begin{array}{l}\text { By } 2025 \text {, the percentage of pure electric buses } \\
\text { and pure electric taxis will increase to } 5 \% \text {. } \\
\text { Develop some pure electric cars. The } \\
\text { percentage of pure electric cars will increase to } \\
1 \% \text {. }\end{array}$ \\
\hline $\begin{array}{l}\text { Scenario 1-3 } \\
\qquad(2-3) \\
\text { improving } \\
\text { vehicle fuel } \\
\text { efficiency }\end{array}$ & $\begin{array}{l}\text { By } 2025 \text {, the gasoline consumption per } 100 \mathrm{~km} \\
\text { of official cars and private cars will drop to } 7 \\
\text { liters per } 100 \mathrm{~km} \text {, with the progressive } \\
\text { development of the vehicle manufacturing } \\
\text { technology and the knowledge popularity of } \\
\text { proper maintenance and use to cars. }\end{array}$ \\
\hline
\end{tabular}

\section{Calculation results}

\subsection{Energy demand}

Due to space limitation, the data is only about total energy demand in the table. Sectoral energy demand and energy structure in total energy demand will be analyzed in the form of texts.

Table 5. Total energy demand (Mtce)

\begin{tabular}{|c|c|c|c|c|}
\hline Scenario & Sub-scenario & 2015 & 2020 & 2025 \\
\hline \multirow{3}{*}{ Scenario 1 } & Scenario 1-1 & 82.66 & 103.50 & 127.63 \\
\cline { 2 - 5 } & Scenario 1-2 & 83.09 & 104.79 & 129.92 \\
\cline { 2 - 5 } & Scenario 1-3 & 82.70 & 104.05 & 128.66 \\
\hline \multirow{3}{*}{ Scenario 2 } & Scenario 2-1 & 82.66 & 104.88 & 133.13 \\
\cline { 2 - 5 } & Scenario 2-2 & 83.09 & 106.17 & 135.42 \\
\cline { 2 - 5 } & Scenario 2-3 & 82.70 & 105.11 & 134.17 \\
\hline
\end{tabular}

According to the calculation results under two scenarios, Beijing's total energy demand will be between 127.63 Mtce to 135.42 Mtce. Compared to the baseline plan, the high plan is with faster GDP growth rate, so energy demand in three sub-scenarios in the high plan will be greater than that in the baseline plan. Energy demand is the minimum in scenario 1-1, 2.29 Mtce less than scenario 1-2, 1.03 Mtce less than scenario 1-3. From 2015 to 2025, the average annual growth rate of energy demand is respectively $4.44 \%, 4.57 \%$ and $4.52 \%$ under three sub-scenarios of baseline plan, which is respectively $4.88 \%, 5.01 \%$ and $4.96 \%$ in the high plan.

Under developing public transport scenario of the baseline plan, the percentage of energy demand in the industry sector accounting for total energy demand will drop because of the adjustment of industrial structure, which is $22.10 \%$ in 2025 . The transport sector and the service and commerce sector are the main sectors driving the growth of energy demand. Energy demand in the transport sector will increase to 22.27 Mtce in 2025, the percentage to $22.55 \%$. Energy demand in the service and commerce sector will increase to 48.01 Mtce in 2025, the percentage to $38.61 \%$ in 2025 . The growth rate of energy demand in the household sector will basically maintain synchronization with that of total energy demand.

From the perspective of energy structure, the demand of natural gas will rapidly increase and coal will decrease, as a result of implementing the policy of natural gas replacing coal. The demand of coke will decrease with the adjustment of industrial structure. Due to the increase of vehicle possession, the demand of gasoline will keep rising. The demand of electricity and heat in the future will still maintain a rapid growth rate with population growth and the development of the tertiary industry. In scenario 1-1, the demand of oil will be accounting for $21.52 \%$ of total energy demand, 2.70 Mtce less than scenario 1-2, 1.14 Mtce less than scenario 1-3.

\subsection{Environmental emissions}

Table 6. Environmental emissions (Mt)

\begin{tabular}{|c|c|c|c|c|c|c|}
\hline \multirow{2}{*}{ Sub-scenario } & \multicolumn{3}{|c|}{2020} & \multicolumn{3}{|c|}{2025} \\
\cline { 2 - 7 } & $\mathrm{CO}_{2}$ & $\mathrm{SO}_{2}$ & $\mathrm{NOx}$ & $\mathrm{CO}_{2}$ & $\mathrm{SO}_{2}$ & $\mathrm{NOx}$ \\
\hline Scenario 1-1 & 109.35 & 0.12 & 0.44 & 127.06 & 0.11 & 0.49 \\
\hline Scenario 1-2 & 111.71 & 0.12 & 0.46 & 131.27 & 0.11 & 0.53 \\
\hline Scenario 1-3 & 109.98 & 0.12 & 0.45 & 128.90 & 0.11 & 0.50 \\
\hline Scenario 2-1 & 110.31 & 0.12 & 0.44 & 130.73 & 0.12 & 0.50 \\
\hline Scenario 2-2 & 112.67 & 0.12 & 0.46 & 134.94 & 0.12 & 0.54 \\
\hline Scenario 2-3 & 110.78 & 0.12 & 0.45 & 132.57 & 0.12 & 0.51 \\
\hline
\end{tabular}

As is shown in table 6, environmental emissions of main pollutants except $\mathrm{SO}_{2}$ will continue to increase, which will bring greater pressure to reduce emissions. However, pollutant emissions per million Yuan of GDP will rapidly decrease because of the constant optimization of industrial structure and energy structure. In the baseline plan, compared with $2012, \mathrm{CO}_{2}$ emissions in scenario $1-1$ will decrease by $54.47 \%$ in $2025,52.82 \%$ in scenario $1-2$, and $53.78 \%$ in scenario $1-3$. In the high plan, those will respectively decrease by $55.80 \%, 54.24 \%$ and $55.14 \%$.

\section{Conclusion}

Energy demnad and environmental emissions in Beijing are projected to increase under two plans due to economic development and increasing social demand. Scenarios may vary in their growth path in energy demand and environmental emissions, but sectoral energy demand and energy structure in total energy demand won't witness big changes.

The study has shown how the LEAP system, combined with regression models, can provide a valuable tool for assessing future urban transport options in Beijing. The studied scenarios demonstrate that plausible alternative pathways do exist. The method, tool, and examples presented are a starting framework for 
beginning an opportunity for creative engagement with the future.

\section{References}

1. Toshihiko Nakata, Progress in Energy and Combustion Science, 30, 417 (2004)

2. Y. Gao, Shanghai Environmental Sciences, 27, 210 (2008)

3. S. W. Hadley, W. Short, Energy Policy, 29, 1285 (2001)

4. Www.energycommunity.org

5. Q.Y.Wang, Handbook for Energy Conservation, (Energy Conservation and Environmental Protection Press, Beijing, 2006)

6. Richard Gilbert, Kathleen Nadeau, Transportation and Economic Development Conference, Canada, 2001 